Marine Biology 27, 333-337 (1974)

(C) by Springer-Verlag 1974

\title{
Laboratory Observations on Spawning and Embryonic Development of a Blue-Ringed Octopus
}

\author{
H. Overath ${ }^{1}$ and S. von Boletzky ${ }^{2}$ \\ Institute of Neurobiology; Jiilich, Germany (FRG) and \\ ${ }^{2}$ C.N.R.S., Laboratoire Arago; Banyuls-sur-Mer, France
}

\section{Abstract}

A female blue-ringed octopus, Hapalochlaena sp. (probably Zunulata), was maintained in an aquarium for nearly 3 months, during which time it spawned and cared for the eggs until hatching. The young are planktonic. Embryonic development does not differ markedly from that observed in other octopods, uniting certain features of the development of Octopus vulgaris and Eledone cirrosa. In terms of reproductive biology and development, the species differs from the lesser blue-ringed octopus Hopalochlaena maculosa in its mode of spawning, egg size and mode of 1 ife of its young. These differences correspond to conditions recorded for Octopus spp. and EZedone spp.

\section{Introduction}

The genus Hopalochlaena was created by Robson (1929) for the two known species of "blue-ringed octopus" from the Indo-Pacific Ocean, Octopus Zumulatus Quoy and Gaimard, 1832, and Detopus pictus Brock, 1882. As the name 0. pictus was preoccupied, Octopus maculosus Hoyle, 1883, was validated (Robson, 1929). Concerning his new genus, Robson himself stated: "As for the generic status of these two species I am very doubtful", and Voss (1971) actually considers them as species of Octopus Lamarck (we retain here Robson's generic designation only because it is the mostly widely used, without stressing its taxonomic validity).

Adam (1938) described a new species of Octopus (0. nierstraszi) from the Andaman Islands, and stated that this species shows several characteristics of Robson's genus Hopalochlaena. A revision of the systematics and distribution of blue-ringed octopuses, by Dr. G.L. Voss (University of Miami), is actually planned (Voss, personal communication). Until this study is completed, we consider the identification of the species dealt with in the present note as provisional. However, for easier reading, we use "H. Zunulata" instead of the safer "Hopalochlaena sp. (probably Zunulata)".

In recent years, the little, colourful, blueringed octopus has won singular fame as "MiniKiller" (Cropp, 1972) and "Death in a small package" since "human fatalities and near fatalities from blue-ringed octopus bites follow an almost repetitive pattern" (Friese, 1972). Hopalochlaena maculosa, the species living "in the more subtropical and temperate waters of the eastern coast of Australia" (Friese, 1972), has been studied by several authors, and this species has also been reared in the laboratoy (Tranter and Augustine, 1973). Little is known, apparently, of the biology of the somewhat larger $H$. ZunuZata whose"distribution seems to extend from the northwest coast of Australia throughout the Indo-Malayan Archipelago" (Friese, 1972).

The present note is intended to draw attention to the particularities concerning reproduction, embryonic development and characteristics of newlyhatched young of Hopalochlaena lunulata as compared to $H$. maculosa. The authors hope that biologists working in the area where $H$. Zunulata is apparently abundant will further contribute to the knowledge of this interesting species.

\section{Material and Methods}

An adult female octopus (total length ca. $20 \mathrm{~cm}$ ) was bought from a local dealer, by the first author, in late March 1973; the octopus was the last surviving of a batch of 6 received from Manila, Philippine Islands. The octopus was placed in an aquarium with a closed-system seawater supply $\left(23^{\circ}\right.$ to $\left.24^{\circ} \mathrm{C}\right)$, at the Institute of Neurobiology, Jülich (FRG). It was fed crabs and the meat of mussels. When the octopus spawned, some eggs were taken from the aquarium for observation and photography and maintained in separate tanks, at a temperature of $26^{\circ} \mathrm{C}$. Newly-hatched octopuses were kept in several aquaria and were presented with different food organisms such as Artemia salina and other small Crustacea.

A brief account of this experiment has been published earlier, by the first author who is mainly interested in problems of laboratory maintenance of marine animals (Overath, 1973). Upon reading this report, the second author of the present note inquired about the species of octopus observed. The identification as Hopalochlaena Zumulata was then ascertained, as far as this is possible, and it was decided to publish the observations in more detail, in order to compare them 

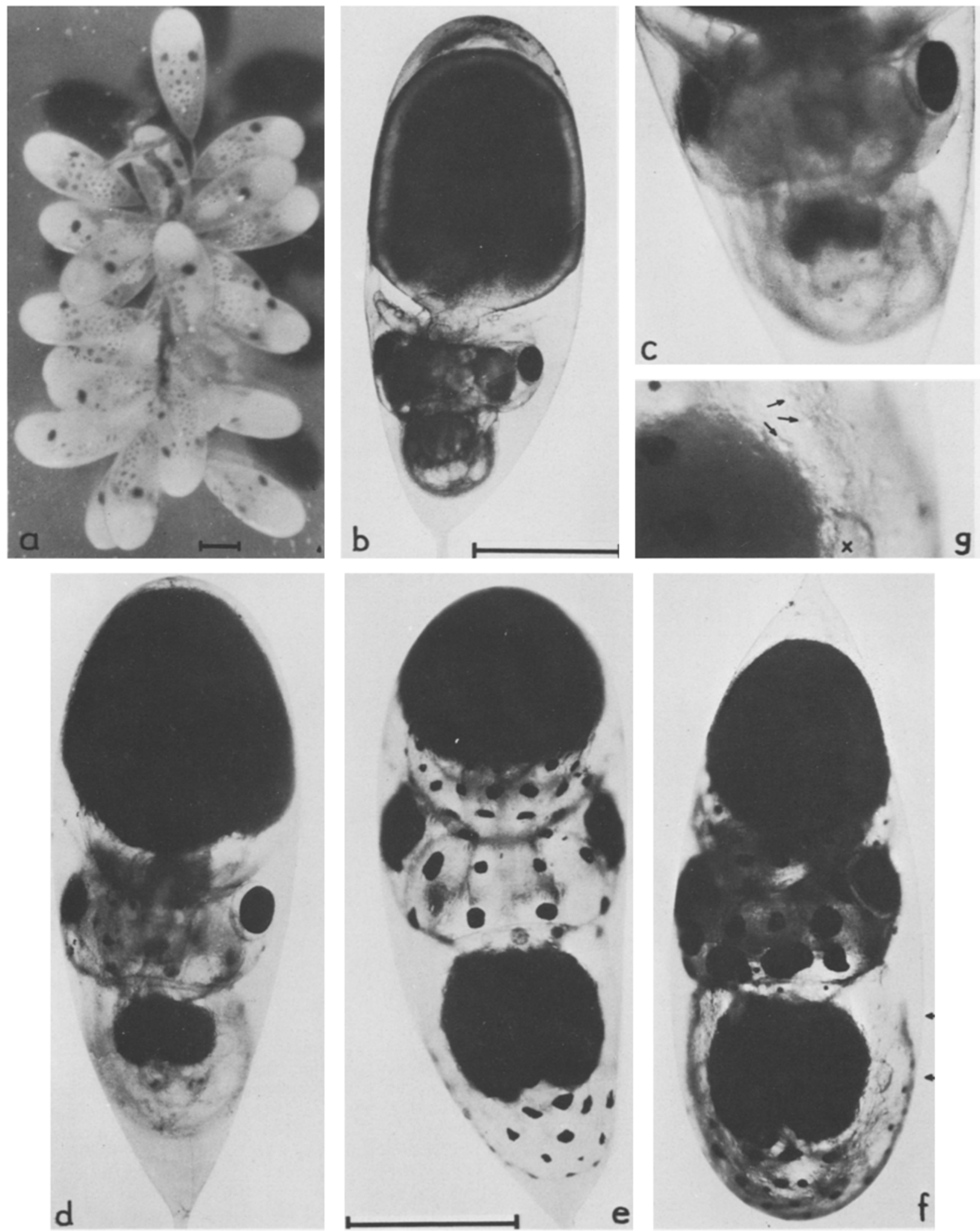

Fig. 1. HopaZochZaena ZumuZata. Embryonic development. (a) Egg cluster with embryos at 1 ate developmental stage, prior to second reversion; (b) embryo at about Stage XV of Naef (1928), with still very large outer yolk sac; (c) similar stage, at higher magnification - note small size of inner yolk sac, comparatively long arms, dark pigmentation of retina; (d-f) later stages showing decreasing size of outer and increasing size of inner yolk sac, chromatophores on head (d) and on body and arms (e, f); (f) shows normal hatching position after second reversion; arrows indicate area shown in ( $g$ ) with Kölliker organs, $x$ marks the mantle ganglion. (Scale $=1 \mathrm{~mm}$ ) 
to the data of Tranter and Augustine (1973) on $H$. maculos $\alpha$ and to discuss them with regard to general characteristics of octopod development. The first author provided all data from which the second author compiled the present note.

\section{Obsemations}

During the first 2 weeks of observation, the female Hapalochlaena Zumulata fed regularly, and frequently moved about in the tank. When the octopus was disturbed, e.g. by a strong light, the typical iridescent blue rings in the integument became particularly distinct. Sometimes, however, the colour was rather uniformly greyish. The general behaviour was in every respect that typical of benthonic octopods (cf. Lane, 1960). After two-and-a-half weeks, the octopus ceased feeding and actively rejected offered food; 3 days later, it started spawning. Several clusters of about 20 eggs each (Fig. la) were attached to the wall of the aquarium, close to the water inflow [the size of these eggs (ca.3.5 mm) is consistent with Adam's (1954) description of apparently immature ovarian eggs $(2.5 \mathrm{~mm})$ in $H$. Zumulata]. The octopus cared for the eggs in the manner known for other benthonic octopods. Ten days from the beginning of spawning, the octopus again accepted food. It died about 3 weeks after the last young had hatched.
Embryonic development of Hopalochlaena Zunulata largely corresponds to that of octopus vuigaris, whose eggs are slightly smaller (Naef, 1923, 1928; Portmann, 1933), and of O. salutii (Boletzky, unpublished), O. joubini (Boletzky, 1969), Eledone cirrosa (Mangold et al., 1971; Fuchs, 1973) and HopaZochlaena maculosa (Tranter and Augustine, 1973), all having larger eggs. During organogenesis, the embryos reverse their position in the egg-case (chorion), the animal pole taking up its position at the side of the chorion stalk (cf. Boletzky, $1971 \mathrm{a}, \mathrm{b})$. As in other cephalopod embryos, the yolk apparatus becomes divided into an outer and an inner yolk sac; the latter decreases in size, during organogenesis and onward until about Stage $\mathrm{XV}$ of Naef (1928) (Fig. 1c); in later stages, its size again increases by yolk transfer from the outer yolk sac (Fig. ld-f; cf. Portmann, 1926). In H. Zunulata, the relative size of the outer yolk sac is somewhat larger, until late stages, than in 0 . vulgaris. The chromatophore development and distribution closely resemble those of 0 . vulgaris (cf. Fioroni, 1965); chromatophores are absent from the dorsal mantle integument (unlike in $H$. maculosa), but present on the dorsal wall of the visceral mass. As in $H$. macuzosa, the iridescent blue rings do not appear during embryonic development. The integumental Kölliger organs, found in most octopod embryos, are present in $H$. Zunulata (Fig. $1 \mathrm{~g}$ ). In contrast to O. vulgaris, the later
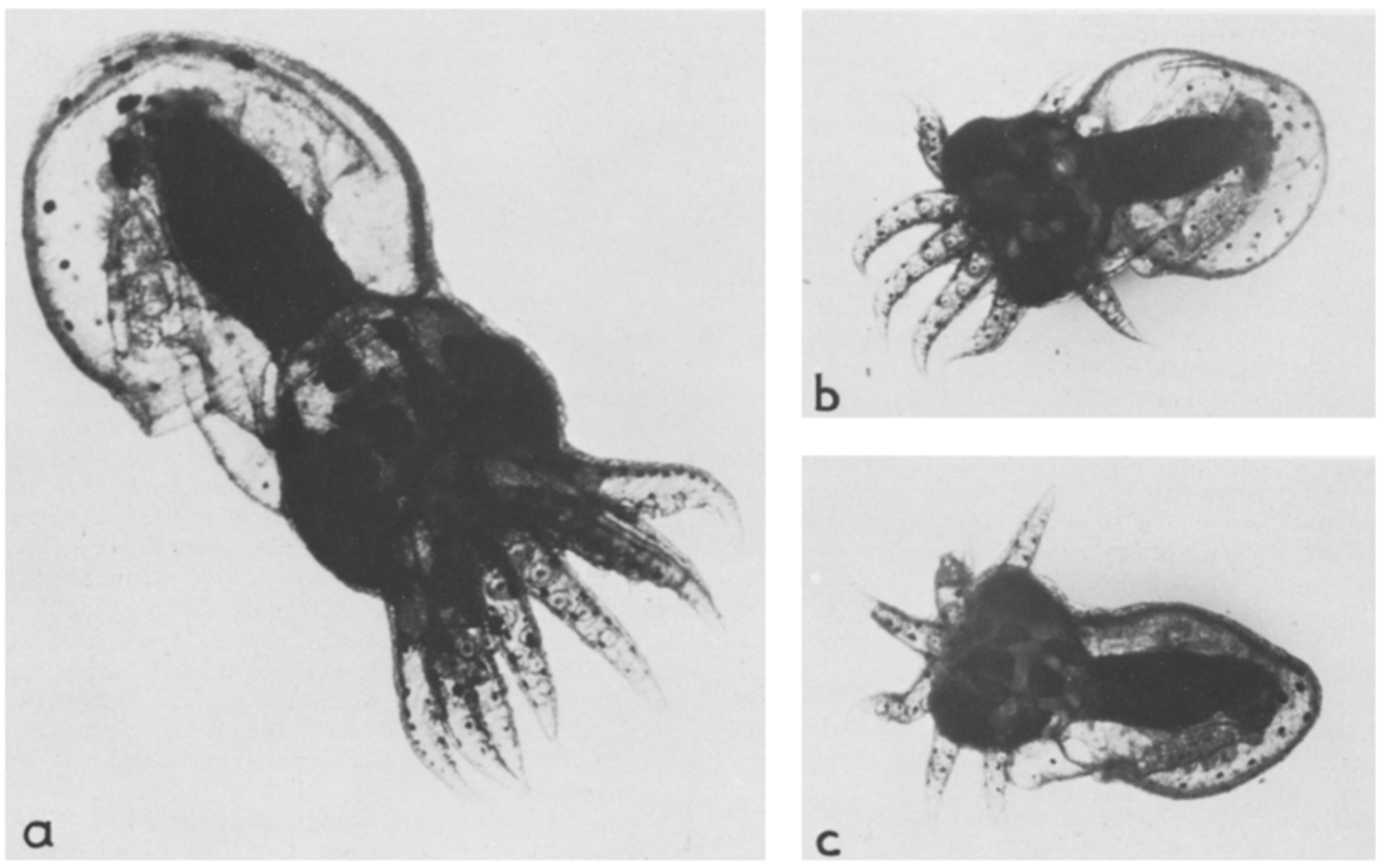

Fig. 2. HapaZochZaena ZunuZata. Young, about 1 day after hatching. (a) Normal swimming position; (b,c) exceptional "sitting" posture (see text). Note comparatively small size of visceral mass (cf. Fig. lf), due to decreased inner yolk sac 
embryonic stages are characterized by considerable growth of the arms, with continual formation of suckers in an increasingly distinct biserial arrangement (see below).

Around Stage XIX of Naef, the embryos again reverse their position so that the mantle lies at the free end of the chorion (cf. Portmann, 1933). As in other octopods, this second reversion does not always occur. The octopuses then hatch at the side of the chorion stalk (Boletzky, 1966).

At a temperature of $26^{\circ} \mathrm{C}$, embryonic development took about 25 days; it was slower at lower temperatures (Table 1; cf. Mangold and Boletzky, 1973, for Octopus vulgaris). The outer yolk sac was almost completely taken in by the young HopaZochzaena Zunulata by the time of hatching. This demonstrates that hatching was normal (premature hatching with a comparatively large outer yolk sac is a phenomenon frequently observed in cephalopod embryos raised under artificial conditions).

Newly-hatched Hopalochlaena Zunulata are planktonic. In terms of morphometrics, they are quite similar to the planktonic young of Eledone cirrosa that are, however, much larger (Mangold et al., 1971). The arms of newly-hatched $H$. Zunulata, with their approximately 10 suckers are not only further developed than in the smaller planktonic young of octopus vulgamis (ML, mantle length, $2.0 \mathrm{~mm}, 3$ suckers per arm), but also further than in the much larger planktonic young of 0 . salutiz (ML $3.5 \mathrm{~mm}, 4$ suckers per arm).

The young HopaZochZaena Zznulata showed the typical swimming activity of planktonic cephalopods, counteracting passive sinking by jet propulsion; they generally swam close to the water surface. Sometimes, they rolled up into a ball and sank to the bottom where they immediately resumed active swiming. Despite their clearly planktonic mode of life (which might also suitably be termed micro-nectonic), young $H$. Zunulata are able to attach themselves to a hard substrate by the suckers of their comparatively long arms (Fig. 2b, c), thus showing the typical sitting posture of benthonic octopods (unlike newly-hatched Octopus vulgaris that are unable to do so).

A considerable number of juveniles survived for 2 or 3 days and showed a slight increase in size. Although feeding was not observed, it seems likely that at least some of them fed, as a dark spot in the rear part of the visceral mass suggested the presence of stomach contents. However, no octopus survived over 1 week.

\section{Discussion}

Table 1 indicates the differences in spawning and development between the two species of HapalochZaena, as far as they are now known. As in cephalopods in general, the size of the eggs is independent of adult size. Thus $H$. Zunulata which has a larger adult size than $H$. maculosa (cf. Robson, 1929), has smaller eggs than the latter species. The fact that the small young $H$. Zunulata hatched from small eggs are planktonic, whereas
Table 1. Hopalochzaena. Comparison of data on spawning and development of $H$. Zunulata (present study) and $H$. maculos $\alpha$ (from Tranter and Augustine, 1973)

\begin{tabular}{|c|c|c|}
\hline & H. Zunuzata & H. macuzosa \\
\hline Mode of spawning & $\begin{array}{l}\text { Egg clusters } \\
\text { attached to } \\
\text { substrate }\end{array}$ & $\begin{array}{l}\text { Egg clusters } \\
\text { carried by } \\
\text { mother }\end{array}$ \\
\hline $\begin{array}{l}\text { Egg size (length of } \\
\text { chorion excluding } \\
\text { stalk) }\end{array}$ & ca. $3.5 \mathrm{~mm}$ & $6-7 \mathrm{~mm}$ \\
\hline \multicolumn{3}{|l|}{$\begin{array}{l}\text { Length of embryonic } \\
\text { development at }\end{array}$} \\
\hline $21^{\circ}-22.5^{\circ} \mathrm{C}$ & & $\begin{array}{l}\text { ca. } 60 \text { days } \\
\text { (Stage XV - } \\
\text { Stage XX: } \\
\text { 25-35 days) }\end{array}$ \\
\hline $\begin{array}{l}23^{\circ}-24^{\circ} \mathrm{C} \\
26^{\circ} \mathrm{C}\end{array}$ & $\begin{array}{l}\text { ca. } 35 \text { days } \\
\text { ca. } 25 \text { days }\end{array}$ & \\
\hline $\begin{array}{l}\text { Dorsal mantle-length } \\
\text { (ML) at hatching }\end{array}$ & ca. $2.3 \mathrm{~mm}$ & $3.5-4 \mathrm{~mm}$ \\
\hline $\begin{array}{l}\text { Arm-length in } \% \text { of } \\
\text { ML at hatching }\end{array}$ & ca. 50 & ca. 100 \\
\hline $\begin{array}{l}\text { Number of suckers } \\
\text { per arm at hatching }\end{array}$ & ca. 10 & ca. 20 \\
\hline Mode of life of young & Planktonic & Benthonic \\
\hline
\end{tabular}

the larger young $H$. maculosa, hatched from larger eggs are benthonic, is not surprising in view of the corresponding situation already known in other octopods (cf. Naef, 1928; Voss, in Lane, 1960 (p. 129); Boletzky, 1969; Mangold, 1972). However, it is important to note that the egg size of $H$. maculosa falls into the intermediate size category in which the (planktonic or benthonic) mode of life of the young cannot be correlated with absolute, but only with relative egg size (Boletzky, in press). For example, young octopus saluti $i$ and Eledone cirrosa hatched from eggs of size (ca. 5.5 and $7.5 \mathrm{~mm}$, respectively) similar to the egg size of $H$. maculosa are planktonic, but the relative size of the eggs is much larger in $H$. maculosa 12 to $13 \%$ of adult ML) than in 0 . saluti $i$ and in E. cirrosa (ca. $5 \%$ of adult ML).

In terms of geographic distribution, the wider spread of Hopalochlaena Zunulata can reasonably be considered in relation to the presence of planktonic young individuals that give the species a higher "dispersal capacity" than H. maculosa with its benthonic young (cf. Mangold, 1972). The re- 
lative size and the morphometrics of newly-hatched H. Zunulata suggest that the young may spend a shorter time in the plankton than young Octopus vulgaris (cf. Itami et al., 1963), and a considerable "elasticity" in terms of the early postembryonic mode of life is conceivable. However, further studies are necessary to obtain precise information on the length of planktonic life and its range of variation in relation to ecological conditions. For this purpose, field studies should be carried out along with laboratory experiments covering as much as possible of the life cycle. Although, in general, the rearing of planktonic young cephalopods is more difficult than that of benthonic young, it would seem that the laboratory culture of $H$. Lunulata is easier than that of 0 . vulgaris as described by Itami et al. (1963).

Acknowledgements. The authors are greatly indebted to Mr. D. Sonnemann (Jïlich, FRG), for making the photographs, to Dr. K. Mangold (Banyuls, France) and Mrs. L. Rowe (Banyuls and St. John's, Newfoundland, Canada), for critically reading the manuscript, and to Dr. G.L. Voss (Miami) for valuable information and suggestions and for reading the manuscript.

\section{Literature Cited}

Adam, W.: Sur quelques céphalopodes octopodes des I1es Adamans. Bul1. Mus. r. Hist. nat. Belg. 14 (7), 1-25 (1938)

- Cephalopoda (3. part) IV - Céphalopodes à l'exclusion des genres Sepia, Sepielza et Sepioteuthis. Siboga Exped. 55c, 123-193 (1954)

Boletzky, S. von: Zum Schlüpfen von Octopus vuzgaris Lam. Verh. naturf. Ges. Base1 77, 165-170 (1966)

- Zum Vergleich der Ontogenesen von Octopus vuzgaris, 0 . joubini und 0 . briareus. Revue suisse Zool. 76, 716-726 (1969)

- Rotation and first reversion in the Octopus embryo - a case of gradual reversal of ciliary beat. Experientia 27, 558-560 (1971a)

- Zu den Lageveränderungen von Octopoden-Embryonen (Mollusca: Cephalopoda). Revue suisse Zool. 78, 538-548 (1971b)

- The "larvae" of Cephalopoda - a review. Tha1 assia jugos 1 . (In press)

Cropp, B.: The mini-killers. Oceans Mag. 5, p. 40 (1972)
Fioroni, P.: Die embryonale Musterentwicklung bei einigen mediterranen Tintenfischarten. Vie Milieu 16 (2A), 655-756 (1965)

Friese, U.E.: Death in a small package. Mar. Aquarist $3(4), 29-33$ (1972)

Fuchs, E.: Zur Embryonalentwicklung von ÉZedone cirrosa Lam. (Cephalopoda, Octopoda): Eine Beschreibung der Embryonalstadien an Hand der Aussenmorphologie. Zoo1. Jb. (Abt. Anat. Ont. Tiere) $91,19-30(1973)$

Itami, K., Y. Izawa, S. Maeda and K. Nakai: Notes on the laboratory culture of the octopus larvae. Bul1. Jap. Soc. scient. Fish. 29, 514-520 (1963)

Lane, F.W.: Kingdom of the octopus, $300 \mathrm{pp}$. New York: Sheridan House 1960

Mangold, K.: Le potentiel évolutif des céphalopodes. In: 5th European Marine Biology Symposium, pp 307-316. Fd. by B. Battaglia. Padova: Piccin 1972

- and S. von Boletzky: New data on reproductive biology and growth of octopus vuzgaris. Mar. Biol. 19, 7-12 (1973)

- - and D. Frösch: Reproductive biology and embryonic development of Eledone cirrosa (Cephalopoda: Octopoda). Mar. Biol. 8, 109-117 (1971)

Naef, A.: Die Cephalopoden. Fauna Flora Golf. Neapel (I., Systematik) 35, 1-863 (1923)

- Die Cephalopoden. Fauna Flora Golf. Neapel (II., Embryologie) 35, 1-357 (1928)

Overath, H.: Meine Erfahrungen mit Tintenfischen. Z. Aquar.- u. TerrarVer. 12, 418-420 (1973)

Portmann, A.: Der embryonale Blutkreislauf und die Dotterresorption bei Loligo vulgamis. Z. Morph. ökol. Tiere 5, 406-423 (1926)

- Observations sur la vie embryonnaire de la pieuvre (Octopus vulgaris Lam.). Archs Zool. exp. gén. 76, 24-36 (1933)

Robson, G.C.: A monograph of the recent Cephalopoda (Part I, Octopodinae), $236 \mathrm{pp}$. London: British Museum (N.H.) 1929

Tranter, D.J. and O. Augustine: Observations on the life history of the blue-ringed octopus HopaZochzaena macuZosa. Mar. Bio1. 18, 115-128 (1973)

Voss, G.L.: Shy monster, the octopus. Natn. geogr. Mag. 140, 776-799 (1971)

H. Overath

Institut für Neurobiologie Kernforschungsanlage Jïlich D - 517 Jülich 1, Postfach 365 Germany (FRG)

Date of final manuscript acceptance: September 9, 1974. Communicated by Professor J.M. Pérès, Marseille 